\title{
Clinical characteristics and management of growth hormone excess in patients with McCune-Albright syndrome
}

\author{
Yong Yao ${ }^{1, *}$, Yang Liu' ${ }^{1, *}$, Linjie Wang2, Kan Deng', Hongbo Yang², Lin Lu², \\ Feng Feng ${ }^{3}$, Bing Xing ${ }^{1}$, Hui You ${ }^{3}$, Zimeng Jin², Renzhi Wang', Hui Pan², \\ Shi Chen ${ }^{2}$ and Huijuan Zhu' ${ }^{2}$ \\ ${ }^{1}$ Department of Neurosurgery, ${ }^{2}$ Key Laboratory of Endocrinology of National Health and Family \\ Planning Commission, Department of Endocrinology, and ${ }^{3}$ Department of Radiology, Peking Union \\ Medical College Hospital, Chinese Academy of Medical Science, Peking Union Medical College, \\ Beijing, China \\ *(Y Yao and Y Liu contributed equally to this work)
}

Correspondence
should be addressed
to H Zhu
Email
shengxin2004@163.com

\begin{abstract}
Objective: McCune-Albright syndrome (MAS) is a sporadic, postzygotic disease presenting with fibrous dysplasia, cafe-au-lait spots and multiple endocrinopathies. Growth hormone $(\mathrm{GH})$ excess is an uncommon but potentially severe complication of MAS. This study aims to describe the clinical manifestations of GH excess in the context of MAS and analyze the responses of these patients to treatments.

Design: Retrospective clinical study.

Methods: Clinical data from 52 MAS patients were analyzed. Serum GH and IGF1 levels, as well as nadir GH levels after an oral glucose tolerance test and alkaline phosphatase (ALP) levels were determined before and after the treatment. Results: In total, 13 MAS patients (25\%) had the complication of GH excess, including 10 males (76.9\%). Among them, all had FD, and 6 patients had sphenoidal bone involvement. Visual deficits were present in 8 patients, and hearing deficits were present in 5 . Olfactory dysfunction was observed in 3 patients. Evident pituitary adenomas were confirmed in 9 patients by MRI. These patients underwent surgery with or without pretreatment of long-acting somatostatin analogue octreotide, and 6 achieved complete remission. The serum ALP levels decreased significantly after treatment for $\mathrm{GH}$ excess.

Conclusions: MAS with GH excess is more common in male patients. GH excess can lead to more severe skeletal lesions in MAS patients involving more of the craniofacial bones. Complete trans-sphenoidal complete tumor excision with neuronavigational guidance is effective and could lower ALP levels. LAR is recommended as a preoperative treatment and when patients fail to achieve complete remission after surgery.
\end{abstract}

\section{Introduction}

McCune-Albright syndrome (MAS, OMIM 174800) is a sporadic, postzygotic disease with an estimated prevalence of between 1/100,000 and 1/1,000,000 (1). It was first described as a clinical triad of polyostotic/monostotic fibrous dysplasia (FD), café-au-lait pigmented skin lesions and precocious puberty by McCune (2) and separately by Albright (3) in the 1930s. Other endocrinopathies in the
() 2017 European Society of Endocrinology Printed in Great Britain
European Journal of Endocrinology

(2017) 176, 295-303 context of MAS were subsequently identified, including hyperthyroidism (4), hypercortisolism (5), pituitary adenomas-secreting growth hormone (GH) and/or prolactin (PRL) $(6,7)$, and hypophosphatemic osteomalacia (8). GH excess, which is present in $10-20 \%$ (9) of MAS cases, is a serious endocrine complication associated with craniofacial morbidities, including visual and hearing 
deficits, as well as cardiovascular disease and metabolic syndrome. However, the treatment of GH excess in MAS patients remains challenging. Neurosurgical excision is often difficult due to severe fibrous dysplasia at the base of the skull (10), and radiotherapy (RT) may precipitate bone sarcomatous transformation (11). To date, several cases have been reported involving treatment for $\mathrm{GH}$ excess in MAS, however, only a few achieved satisfactory outcomes. The aim of this study is to describe the clinical manifestations, treatment and outcomes of patients with MAS patients complicated by GH excess.

\section{Subjects and methods}

\section{Patients}

All of the studies were performed according to the rules of the hospital medical ethics committee. Informed consent was obtained in accordance with the institutional guidelines.

Clinical data from 52 MAS patients at Peking Union Medical College Hospital from November 1991 to April 2016 were retrospectively analyzed, and those with the complication of GH excess were followed up.

\section{Diagnosis of MAS and GH excess}

A diagnosis of MAS was made when at least two of the following cardinal features were present: café-au-lait skin pigmentation, polyostotic/monostotic bone fibrous dysplasia (FD) and hyperfunctioning endocrinopathies. Technetium whole body bone scanning, CT scans and $\mathrm{X}$-ray imaging were used to confirm bone lesions. The serum alkaline phosphatase (ALP) levels were assessed. Visual, hearing and olfactory functions were evaluated by the otolaryngology and ophthalmology consultation group. A T\&T Olfactometer was used for standardized olfactory test. Endocrine hormone levels were assessed to identify endocrinopathies associated with MAS.

The diagnosis of GH excess was based on clinical symptoms and confirmed by high levels of GH (IMMULITE 2000 GH analyzer, Siemens Healthcare Diagnostic Inc.), age- and sex-adjusted insulin-like growth factor1 levels (IGF1, IMMULITE 2000 IGF1 analyzer, Siemens Healthcare Diagnostic Inc.), and nadir GH levels after an oral glucose tolerance test (OGTT) with GH levels that were greater than $1.0 \mathrm{ng} / \mathrm{mL}$. The nadir GH levels of each patient were recorded at baseline and after surgery. The IGF1 $Z$-scores were adjusted for age and gender according to the normal values of serum
IGF1 (the 5th and 95th percentiles), and $Z$-scores greater than 2.0 were considered elevated.

Pituitary magnetic resonance imaging (MRI) was used to identify compression associated with pituitary tumors. All of the patients underwent blood pressure testing, thyroid ultrasound, echocardiograms and OGTT and comorbidities including diabetes mellitus, hypertension and heart disease were noted.

\section{Pathological analysis}

Pituitary adenoma tissues were surgically removed, fixed in $10 \%$ formaldehyde, embedded in paraffin and cut into $3-\mu \mathrm{m}$-thick sections for immunohistochemical staining. Immunohistochemistry was performed using the avidinbiotin-peroxidase method. The sections were incubated with the following antisera: anti-GH, anti-PRL, antiadrenocorticotropic hormone (Dako, Carpinteria, A0570, A0569, A0571), anti-thyroid-stimulating hormone, anti-follicle-stimulating hormone and anti-luteinizing hormone (Long Island Biotec. Co., Ltd, Shanghai, China; M-0497, M-0255, M-0368).

\section{Treatment}

Nine patients underwent navigation-assisted transsphenoidal pituitary tumor resectioning. The serum levels of IGF1, PRL and ALP, as well as nadir GH levels after OGTT, were evaluated after treatment and during follow-up.

Remission of acromegaly was assessed based on the normalization of GH/IGF1 levels. The criteria for disease control were a normal IGF1 level for age and gender ( $Z$ score $<2.0$ ) and an OGTT-suppressed GH level of no more than $1.0 \mathrm{ng} / \mathrm{mL}$.

The literature regarding treatments for MAS patients with GH excess from 2001 to 2015 was reviewed, and the patients who underwent transsphenoid surgery were noted.

\section{Statistics analysis}

Descriptive statistics were used to characterize the demographic and laboratory data. The IGF1 $Z$-scores were calculated according to an equation described in Ref (12). The height and ALP level $Z$-scores were based on reported distributions of height/ALP levels in Chinese population $(13,14,15) . T$-tests were performed to make comparisons between MAS patients with GH excess and MAS patients 
without GH excess, as well as between GH patients before and after surgery. $P<0.05$ was regarded as statistically significant. The analyses were performed using SPSS 15.0 and GraphPad Prism, version 6 (GraphPad Software Inc.).

\section{Results}

\section{Clinical characteristics}

Thirteen patients (25\%) with GH excess were identified among 52 MAS patients (mean age at diagnosis of MAS: $27.5 \pm 13.4$ years), including ten males $(76.9 \%)$ and three females. The onset of MAS symptoms occurred at $3.3 \pm 6.2$ years of age, and the mean age of diagnosis of $\mathrm{GH}$ excess was $24.2 \pm 11.2$ years. The principal clinical characteristics, endocrine abnormalities and MRI features are listed in Table 1. All of the patients presented with FD. Craniofacial bones were involved in all cases, and the sphenoidal bone was involved in were both involved in $46.1 \%$ of the patients. Six of the patients who had surgery (patient $2,3,7,8,10$, and 11) had FD affecting the sphenoid. Visual field deficits occurred in eight patients (owing to optic canal stenosis in six), FD-related hearing deficits were observed in five and olfactory dysfunction was present in three. The ALP $Z$-scores of the MAS patients with GH excess were higher than those without GH excess (Fig. 1B), and all except one patient had café-au-lait pigmented skin. Peripheral precocious puberty was observed in patients 2 and 12 . Pituitary adenomas were confirmed by MRI in nine patients (69.2\%), seven of which were macroadenomas (maximum diameter $>1.0 \mathrm{~cm}$ ) and two of which were microadenomas (maximum diameter $\leq 1.0 \mathrm{~cm}$ ). Six patients had the complication of PRL hypersecretion. Thyroid involvement was observed in four patients, including primary hyperthyroidism in two patients and abnormalities of the thyroid gland based on ultrasound without frank hyperthyroidism in two patients (total: $30.8 \%)$. Acromegalic cardiopathies were observed in three patients, including left ventricular hypertrophy $(\mathrm{LVH})$, atrial or aortic enlargement and pericardial

Table 1 Clinical characteristics of the 13 MAS patients with the complication of GH excess.

\begin{tabular}{|c|c|c|c|c|c|c|c|c|c|c|c|c|}
\hline $\begin{array}{l}\text { Case } \\
\text { No. }\end{array}$ & Sex & $\begin{array}{c}\text { Age at } \\
\text { diagnosis } \\
\text { of MAS }\end{array}$ & $\begin{array}{c}\text { Age at } \\
\text { diagnosis } \\
\text { of GH } \\
\text { excess }\end{array}$ & $\begin{array}{l}\text { Height } \\
\text { Z-score }\end{array}$ & FD & SD & PP & $\begin{array}{l}\text { Hearing or } \\
\text { olfactory } \\
\text { deficits }\end{array}$ & VD & Hyperendocrinism & $\begin{array}{l}\text { Pituitary } \\
\text { tumor (MRI) }\end{array}$ & $\begin{array}{l}\text { GH excess-related } \\
\text { complications }\end{array}$ \\
\hline 1 & $M$ & 42 & 42 & 1.38 & $P$ & + & - & - & D.1 & $\mathrm{GHH}$ & $\begin{array}{l}\text { Suspected } \\
\text { diagnosis }\end{array}$ & $\begin{array}{l}\text { Shin-soft tissue } \\
\text { infection of } \\
\text { the } \\
\text { submaxillary }\end{array}$ \\
\hline 2 & $\mathrm{~F}$ & 6 & 6 & 7.38 & $P$ & + & + & - & Bilateral* & $\mathrm{GHH}, \mathrm{PH}$ & Macro & - \\
\hline 3 & M & 19 & 19 & 2.05 & $P$ & + & - & $\begin{array}{l}\text { External } \\
\text { auditory } \\
\text { canal } \\
\text { atresia }\end{array}$ & Unilateral & $\mathrm{GHH}, \mathrm{PH}$ & Macro & LVH \\
\hline 4 & $M$ & 36 & 36 & 1.72 & $\mathrm{M}$ & + & - & $\begin{array}{l}\text { Conductive } \\
\text { deafness }\end{array}$ & Unilateral & $\mathrm{GHH}$ & Macro & $\begin{array}{l}\text { HTN, aorta } \\
\text { broadening, } \\
\text { pericardial } \\
\text { effusion, IGT }\end{array}$ \\
\hline 5 & $\mathrm{~F}$ & 27 & 27 & 0.55 & $P$ & + & - & $\begin{array}{l}\text { Conductive } \\
\text { hearing } \\
\text { loss, } \\
\text { hyposmia }\end{array}$ & Bilateral & $\mathrm{GHH}, \mathrm{PH}$ & Macro & IGT \\
\hline 6 & M & 25 & 25 & -0.45 & $P$ & + & - & $\begin{array}{l}\text { Conductive } \\
\text { deafness }\end{array}$ & Bilateral & $\mathrm{GHH}, \mathrm{PH}, \mathrm{HT}$ & $\begin{array}{l}\text { Pituitary } \\
\text { enlargement }\end{array}$ & $\begin{array}{l}\text { Left atrial } \\
\text { enlargement, } \\
\text { IGT }\end{array}$ \\
\hline 7 & $\mathrm{~F}$ & 12 & 12 & 2.4 & $P$ & + & - & Hyposmia & Bilateral & $\mathrm{GHH}$ & Micro & - \\
\hline 8 & $\mathrm{M}$ & 35 & 33 & 1.72 & $\mathrm{M}$ & - & - & Hyposmia & Unilateral & $\mathrm{GHH}, \mathrm{PH}$ & Macro & - \\
\hline 9 & $\mathrm{M}$ & 46 & 46 & 3.05 & $P$ & + & + & - & - & $\mathrm{GHH}$ & Micro & HTN, DM \\
\hline 10 & $\mathrm{M}$ & 43 & 26 & 2.72 & $P$ & + & & - & - & $\mathrm{GHH}, \mathrm{PH}$ & Macro & - \\
\hline 11 & $\mathrm{M}$ & 47 & 46 & 0.05 & $P$ & + & & - & Unilateral & $\mathrm{GHH}$ & Macro & - \\
\hline 12 & $\mathrm{M}$ & 9 & 9 & 1.43 & $P$ & + & + & - & - & $\mathrm{GHH}$ & N/A & - \\
\hline 13 & $M$ & 22 & 22 & 2.05 & $P$ & + & & Tinnitus & - & $\mathrm{GHH}, \mathrm{HT}$ & N/A & - \\
\hline
\end{tabular}

DM, Diabetes Mellitus; FD, fibrous dysplasia; GHH, growth hormone hypersecretion; HT, hyperthyroidism; HTN, hypertension; IGT, impaired glucose tolerance; LVH, left ventricular hypertrophy; M, mono; P, poly; PH, prolactin hypersecretion; PP, precocious puberty; SD, skin dysplasia (café-au-lait skin pigments); VD, visual deficit (*, VD related to pituitary adenoma, others refer to FD-related VD); +, positivity; -, negativity. 

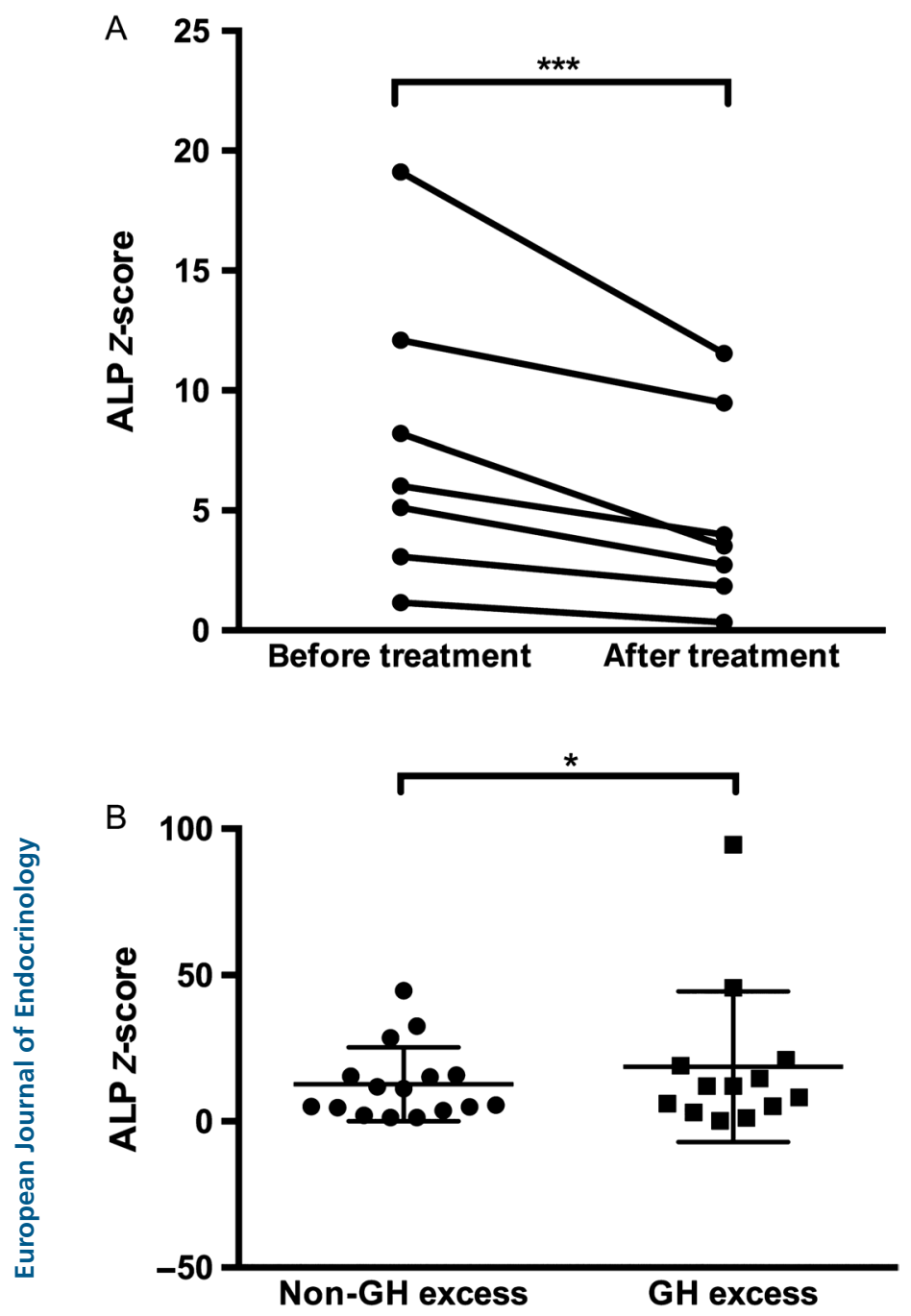

Figure 1

Serum ALP level Z-scores of MAS patients. (A): before and after treatment for $\mathrm{GH}$ excess. (B): with or without $\mathrm{GH}$ excess. $* * * P<0.001, * P<0.05$.

effusion. Four patients had impaired glucose tolerance (IGT), and two patients were hypertensive.

Thirty-nine of the MAS patients did not have the complication of $\mathrm{GH}$ excess (mean age at diagnosis of MAS, $13.8 \pm 9.6$ years), and $28.2 \%$ of these patients were male. There were no significant differences in age of diagnosis between the patients with and without GH excess. FD occurred in $76.9 \%$ of the MAS patients without GH excess. Among them, only three patients were diagnosed with conductive hearing loss and two with visual deficits due to a narrowing of the auditory/optic canals, whereas none presented with hyposmia. Of the 22 cases with complete records, craniofacial bones were involved in $81.2 \%$ of the cases, and the sphenoidal bone was involved in only
15.4\%. Appendicular bones and axial bones were involved in $87.5 \%$ and $56.2 \%$ of the cases, respectively. Twentythree patients $(59.0 \%)$ underwent precocious puberty (PP). Two of the patients had primary hyperthyroidism, and three had thyroid nodules without abnormal thyroid function (total: $22.7 \%$ ).

\section{Treatment outcome}

Four of the patients without definitive radiographic evidence of pituitary adenomas did not undergo surgery, and the $\mathrm{GH}$ excess was not controlled at the time of discharge. The remaining nine patients underwent navigation-assisted transsphenoidal pituitary tumor resection. The pathology showed negative margins, and the immunohistochemical analysis confirmed pure $\mathrm{GH}$ $(n=3)$, mixed GH-PRL $(n=5)$ and mixed GH-PRL-LH $(n=1)$ adenomas. One of the nine patients had received gamma knife treatment for his tumor at another hospital prior to the surgery, and his symptoms of GH excess reoccurred. Notably, he developed osteosarcoma at the pterygopalatine fossa during the postoperative follow-up. Two of the patients had been injected with $20 \mathrm{mg}$ of the long-acting somatostatin analogue octreotide (LAR) (Sandostatin LAR, Novartis) once a month for 3-4 months before the surgery. However, no significant tumor shrinkage was observed by MRI. One patient had taken LAR and then bromocriptine for 10 years before he underwent the surgery, but the GH excess was not controlled. One patient was treated with surgery followed by LAR.

The follow-up time ranged from 0.3 to 9.6 years. Total tumor excision was achieved in all of the patients, as confirmed by postsurgical MRI. No additional pituitary deficiencies were found post-surgically. Six patients achieved complete remission, with a reduction in GH/IGH-1 to normal levels. Meanwhile, three patients partially responded, and their GH levels were controlled by LAR postoperatively (Table 2 ). The serum ALP Z-scores decreased significantly after remission of $\mathrm{GH}$ excess $(\sim 26.3 \%, P<0.001)$ (Fig. 1A).

Previous reports of treatments for $\mathrm{GH}$ excess in MAS patients, and their outcomes are summarized in Table 3. Of the patients who underwent navigated transsphenoidal surgery without preoperative medication or with ineffective medication, 2 out of 7 achieved complete remission after surgical excision alone or followed by post-operative medication/ radiotherapy, and 5 out of 7 patients partially responded to the treatment. 


\section{Discussion}

MAS is caused by a postzygotic-acting mutation in the GNAS1 gene encoding the alpha chain of the heterotrimeric $G$ protein (Gsa) that is involved in stimulating the adenyl cyclase-cAMP pathway $(16,17)$. However, the pathophysiology of GH excess in MAS at the cellular and organ level is not clearly understood. The results of this study shows that $26.4 \%$ of MAS patients had the complication of GH excess, which is in accordance with previous reports $(6,7,18)$.

GH excess in the context of MAS has its own characteristics. In this study, we found that the MAS patients with GH excess were diagnosed at younger ages (mean age of onset, 24.2 years) than patients with classical acromegaly/gigantism (mean age of diagnosis, 48.7 years) (19), which is consistent with previous reports (20). Furthermore, $76.9 \%$ of male MAS patients suffered from GH excess, whereas the percentage of males with classic acromegaly/gigantism has been reported to be lower (52.8\%) (19). GH excess is associated with growth acceleration and/or facial dysmorphism. However, growth acceleration may be obscured in MAS patients with PP, and facial dysmorphism is often difficult to assess due to craniofacial FD. Of the eight patients with an adolescent onset of GH excess in this study, four presented with accelerated growth, and three of these patients exhibited PP. Enlarged feet and hands offer important clues for acromegaly. Co-secretion of PRL was observed in $46.1 \%$ (6/13) of MAS patients with GH excess, which is in accordance with the consensus that the prevalence of hyperprolactinemia is higher in patients with MAS than in those with classical acromegaly (71-92\% vs 30-40\%) $(7,12,21)$.

In addition, there are several important differences between MAS with GH excess and MAS without GH excess. A greater proportion of the $\mathrm{GH}$ excess patients were male, and GH excess may aggravate the skeletal lesions associated with MAS. In this study, FD was presented in $76.9 \%$ of the MAS patients without GH excess compared with $100 \%$ of the patients with GH excess. Despite the fact that craniofacial bones were commonly involved in both cases, FD affecting the sphenoid bone was observed more often in patients with GH excess (46.1\%) compared to those without (15.4\%). In addition, the involvement of the appendicular and axial bones was less commonly observed in patients with GH excess. Therefore, we should prescribe systematic hormone tests and pituitary contrast-enhanced MRIs for MAS patients with confirmed sphenoidal bone damage or the absence of extracranial 
Table 3 Treatments for GH excess in MAS patients and their outcomes: a review of literature from 2001 to 2015

\begin{tabular}{|c|c|c|c|c|c|c|}
\hline Year & Area & No. of cases & $\begin{array}{l}\text { Sex/Age } \\
\text { (years) }\end{array}$ & Treatment for GH excess & Outcome & Ref. \\
\hline 2001 & Germany & 1 & $\mathrm{M} / 8^{\mathrm{a}}$ & LAR & PR & (32) \\
\hline 2002 & NIH, USA & 10 & $\begin{array}{l}M: F, 2: 8 / \\
\text { range: } 4-40\end{array}$ & $\begin{array}{l}\text { CAB }(n=7) \\
\operatorname{LAR}(n=8) \\
\text { CAB and LAR }(n=4)\end{array}$ & $\begin{array}{l}\text { 6/7 PR } \\
4 / 8 \text { effective } \\
4 / 4 \text { PR }\end{array}$ & (12) \\
\hline 2003 & India & 3 & $\begin{array}{l}M / 28^{a} \\
M / 25^{a} \\
M / 19^{a}\end{array}$ & $\begin{array}{l}\text { Transfrontal pituitary adenomectomy+RT } \\
\text { in all three }\end{array}$ & $\begin{array}{l}\text { No response } \\
\text { PR } \\
\text { PR }\end{array}$ & (33) \\
\hline 2005 & Australia & 1 & $\mathrm{M} / 8.5$ & Octreotide $+\mathrm{L} A R$ & PR & (34) \\
\hline 2006 & Turkey & 1 & $\mathrm{M} / 52$ & LAR & PR & (35) \\
\hline 2006 & Greece & 6 & $\mathrm{M} / 9$ & LAR & CR & (36) \\
\hline \multirow[t]{5}{*}{2006} & NIH, USA & 5 & $M / 33$ & $\mathrm{LAR}+\mathrm{CAB}$ and pegvisomant & $\begin{array}{l}\text { Not normalized } \\
\text { IGF1 }\end{array}$ & (28) \\
\hline & & & $F / 39$ & LAR + pegvisomant & $\begin{array}{l}\text { Normalized } \\
\text { IGF1 }\end{array}$ & \\
\hline & & & $\mathrm{M} / 17$ & LAR + pegvisomant & $\begin{array}{l}\text { Normalized } \\
\text { IGF1 }\end{array}$ & \\
\hline & & & $F / 37$ & $\mathrm{LAR}+\mathrm{CAB}$ and pegvisomant & $\begin{array}{l}\text { Normalized } \\
\text { IGF1 } \\
\text { Increased tumor } \\
\text { size }\end{array}$ & \\
\hline & & & $\mathrm{F} / 13$ & LAR + CAB and pegvisomant & $\begin{array}{l}\text { Normalized } \\
\text { IGF1 }\end{array}$ & \\
\hline 2007 & Korea & 1 & $M / 23$ & LAR and bromocriptine & $\begin{array}{l}\text { Normalized PRL } \\
\text { GH/IGF1 decline }\end{array}$ & (37) \\
\hline 2008 & Japan & 1 & $M / 15$ & $\begin{array}{l}\text { Transfrontal partial } \\
\text { adenomectomy }+ \text { octreotide }+ \text { neurological } \\
\text { decompression of the optic nerve }+ \text { LAR } \\
\text { and CAB }\end{array}$ & $\mathrm{CR}$ & (38) \\
\hline 2009 & Brazil & 1 & $\mathrm{M} / 29^{\mathrm{a}}$ & $L A R+C A B$ & $\mathrm{CR}$ & (39) \\
\hline 2010 & Poland & 1 & $\mathrm{~F} / 41$ & LAR & No response & (40) \\
\hline 2011 & Japan & 1 & $M / 39^{b}$ & Adenomectomy + cyberknife RT & $\begin{array}{l}\text { Normalized GH } \\
\text { and ACTH }\end{array}$ & (41) \\
\hline \multirow[t]{3}{*}{2011} & USA & 2 & $\mathrm{~F} / 21^{\mathrm{a}}$ & 1: surgery $(\mathrm{TSA})+$ short-acting octreotide & $\begin{array}{l}\text { Residual tumor } \\
\text { NCR }\end{array}$ & $(10)$ \\
\hline & & & & $\begin{array}{l}\text { 2: } L A R+\text { second resection due to residual/ } \\
\text { recurrent pituitary microadenoma+ } \\
\text { lanreotide }\end{array}$ & & \\
\hline & & & $\mathrm{F} / 29$ & LAR & PR & \\
\hline \multirow[t]{3}{*}{2012} & NIH,USA & 3 & $\mathrm{M} / 19$ & Selective removal (TSA) & PR & (26) \\
\hline & & & $F / 29$ & Selective adenomectomy (TSA) & PR & \\
\hline & & & $\mathrm{M} / 19$ & Total hypophysectomy (TSA) & CR & \\
\hline 2012 & India & 1 & $M / 33$ & Subtotal excision (TSA) + CAB & PR & $(42)$ \\
\hline \multirow[t]{2}{*}{2013} & $\mathrm{NIH}$ & 26 & M:F 6:7 & $\begin{array}{l}\text { LAR }(n=\mathrm{II}) \\
\text { LAR + LAR and Pegvisomant }(n=5) \\
\text { LAR + Pegvisomant }(n=\mathrm{I})\end{array}$ & $\begin{array}{l}\text { Effective } \\
4 / 5 \text { effective } \\
\text { IGF-I decline } \\
\text { but not } \\
\text { normalized }\end{array}$ & (43) \\
\hline & & & & LAR + Surgery $($ LSA) $(n=2)$ & $1 / 2$ effective & \\
\hline \multirow[t]{3}{*}{2014} & France & 3 & $\mathrm{~F} / 22$ & LAR & PR & \\
\hline & & & M/35 & LAR + Pegvisomant & CR & \\
\hline & & & $\mathrm{F} / 64$ & $\begin{array}{l}\text { LAR }+ \text { LAR and DA }+\gamma \text {-knife radiotherapy+ } \\
\text { Pegvisomant }\end{array}$ & CR & \\
\hline
\end{tabular}

$C A B$, cabergoline; CR, complete remission; DA, dopamine antagonist; LAR, long-acting somatostatin analogue octreotide; NCR, not complete remission; PR, partial response; surgery, transsphenoidal pituitary tumor resection; TSA, Transspheinoidal approach; +, followed by. ${ }^{a}$ complicated by PRL hypersecretion. ${ }^{b}$ complicated by hypercortisolism. 
bone involvement to rule out GH excess and pituitary adenomas. Higher concentrations of $\mathrm{GH}$ accelerate craniofacial FD and increase the risk of olfactory, hearing and vision loss (12). We found that hyposmia, sensorineural hearing loss and visual deficits were less common in the MAS patients without GH excess (with vs without GH excess: $38.4 \%$ vs $12.8 \%$ ). Although the mass occupying effects of the GH macroadenomas could in part explain the visual deficits, the visual problems were more frequently related to a narrowing of the optic canal (75\%), which is consistent with previous reports (20). Bone turnover is increased in acromegaly patients who have significantly higher levels of markers of both bone formation and resorption (22). These biomarkers including ALP often correlate with the extent and severity of skeletal involvement in MAS (23). As shown in the result section, serum ALP levels decreased significantly when the GH excess was controlled, indicating that treatment for GH excess may improve FD. There were significant differences in the ALP levels between MAS patients with GH excess and MAS patients without GH excess (Fig. 1), and further studies are warranted regarding the relationship between GH and skeletal lesions. Moreover, GH excess is associated with glucose intolerance, hypertension and acromegalic cardiomyopathy, which might increase the morbidity and mortality (24).

Three of the patients did not exhibit any symptoms of $\mathrm{GH}$ excess during thorough examinations after the diagnosis of MAS. However, hormone tests revealed elevated GH levels, and an MRI confirmed the presence of a pituitary adenoma in one of them. Therefore, systematic hormone testing and pituitary contrast-enhanced MRI may be beneficial for MAS patients. Previous reports have indicated that pituitary adenomas tend to be absent or smaller in MAS patients with GH excess (25), and widespread and diffuse pituitary gland disease has been identified even in patients who appeared to have discrete adenomas on MRI (26). However, pituitary adenomas were confirmed pathologically in $69.2 \%$ of the patients in this study and seven were macroadenomas. This is probably a consequence of the development of imaging techniques, as well as biases due to the small sample sizes and single-center studies.

Current treatments for GH excess in MAS include radiotherapy, surgery and medication (somatostatin receptor ligands, the dopamine agonist Cabergoline and the GH receptor antagonist Pegvisomant). Although a review published in 2014 suggested that surgical excision might not be beneficial for MAS patients with pituitary adenomas because skeletal lesions usually makes the operation more challenging (20), considerable technical progress has been made in the past few years, so we propose that transsphenoidal excision with neuronavigational guidance might be a good choice for treatment. As reviewed in Table 3, 2 out of 7 of the previously published cases of patients who underwent transsphenoidal surgery without preoperative medication or with ineffective medication achieved complete remission after surgical excision alone or when followed by post-operative medication/radiotherapy, and 5 out of 7 patients had a partial response. Moreover, in this study, 6 out of 9 patients who underwent navigation-assisted transsphenoidal pituitary adenomectomy achieved complete remission according to endocrinological criteria. Notably, 4 of the 6 patients had FD affecting the sphenoid. Among the patients who underwent surgery alone, the complete remission rate was $75 \%(3 / 4)$, which is consistent with the reported rate for classic acromegaly patients (74\%) (27). Individual differences among patients, improvements in neurosurgical techniques and the experience of the surgeons may explain different remission rates.

Treatment with medication is also of vast value. Among the cases reviewed in the literature, 46 patients took medication alone, including octreotide, LAR, cabergoline ( $\mathrm{CAB}$, a dopamine agonist), pegvisomant (a GH receptor antagonist) and a combination of above. The symptoms of 22 patients were completely alleviated by LAR treatment alone or when combined with other drugs. LAR, as the first-line drug for GH excess, was able to normalize IGF1 levels in approximately $50 \%$ of the patients and result in a partial response in the rest. The ability of pegvisomant to normalize IGF1 levels is similar to LAR, but it is not as effective at treating other GH excessrelated symptoms such as fatigue and sweating (28). Patients frequently exhibit inadequate responses to $\mathrm{CAB}$, and the administration of medication before and after surgery is favorable for complete relief. Considering the potential for tumor shrinkage and the downregulation of GH/IGF1 levels by somatostatin analogues, preoperative treatment of acromegaly patients with these drugs reduces comorbidity and facilitates adenoma removal $(27,29)$. Two of the patients in this study received preoperative LAR. However, no tumor shrinkage was observed. Therefore, well-designed studies are required to further assess the role of preoperative therapy.

Radiotherapy is considered as the last choice due to the risk of bone sarcomatous transformation. MAS has been shown to be associated with the malignant transformation of FD, as well as malignancies of thyroid and breast (30). Liu et al. (31) reported a case involving 
a MAS patient who was treated with radiation therapy and later developed undifferentiated chondrosarcoma of the malignant fibrous histiocytoma subtype in the sellar region afterward. In this study, it is highly suspected that the osteosarcoma of the pterygopalatine fossa that patient 8 developed was related to the radiotherapy. We suggest that radiotherapy be used only when surgery is not possible and medication fails.

It should be noted that this study was limited by the inherent drawbacks of retrospective analyses. Small sample sizes were also a major problem due to the low incidence rate of MAS. These issues could be partially resolved by delicate statistical analysis and a supportive literature reviewed. Another limitation was the lack of IGF1 data for patient 5 as the GH nadir of this patient was just below the cutoff of $1 \mathrm{ng} / \mathrm{mL}$. In addition, ALP levels were the only biomarker for skeletal lesions analyzed, so further exploration is warranted.

\section{Conclusion}

MAS with GH excess is more common in male patients, and GH excess could lead to more severe skeletal lesions and more involvement of the craniofacial bones. Complete trans-sphenoidal tumor excision with neuronavigational guidance is effective and could lower ALP levels, and LAR is recommended as both a preoperative treatment and when patients fail to achieve complete remission after surgery.

\section{Declaration of interest}

The authors declare that there is no conflict of interest that could be perceived as prejudicing the impartiality of the research reported.

Funding

National Key Program of Clinical Science (WBYZ2011-873).

\section{References}

1 Dumitrescu CE \& Collins MT. McCune-Albright syndrome. Orphanet Journal of Rare Diseases 20083 12. (doi:10.1186/1750-1172-3-12)

2 DJ. M. Osteitis fibrosa cystica; the case of a nine year old girl who also exhibits precocious puberty, multiple pigmentation of the skin and hyperthyroidism. American Journal of Diseases of children 193652 743-744.

3 Albright F, Butler AM, Hampton AO \& Smith P. Syndrome characterized by osteitis fibrosa disseminata, areas of pigmentation and endocrine dysfunction, with precocious puberty in females: report of five cases. New England Journal of Medicine 1937216 727-746. (doi:10.1056/NEJM193704292161701)

4 Mastorakos G, Mitsiades NS, Doufas AG \& Koutras DA. Hyperthyroidism in McCune-Albright syndrome with a review of thyroid abnormalities sixty years after the first report. Thyroid $1997 \mathbf{7}$ 433-439. (doi:10.1089/thy.1997.7.433)

5 Kirk JM, Brain CE, Carson DJ, Hyde JC \& Grant DB. Cushing's syndrome caused by nodular adrenal hyperplasia in children with McCune-Albright syndrome. Journal of Pediatrics 1999134 789-792. (doi:10.1016/S0022-3476(99)70302-1)

6 Chanson P, Dib A, Visot A \& Derome PJ. McCune-Albright syndrome and acromegaly: clinical studies and responses to treatment in five cases. European Journal of Endocrinology 1994131 229-234. (doi:10.1530/eje.0.1310229)

7 Premawardhana LD, Vora JP, Mills R \& Scanlon MF. Acromegaly and its treatment in the McCune-Albright syndrome. Clinical Endocrinology 199236 605-608. (doi:10.1111/j.1365-2265.1992.tb02272.x)

8 Lala R, Matarazzo P, Andreo M, Defilippi C \& de Sanctis C. Impact of endocrine hyperfunction and phosphate wasting on bone in McCune-Albright syndrome. Journal of Pediatric Endocrinology and Metabolism 200215 (Suppl 3) 913-920.

9 Beckers A, Aaltonen LA, Daly AF \& Karhu A. Familial isolated pituitary adenomas (FIPA) and the pituitary adenoma predisposition due to mutations in the aryl hydrocarbon receptor interacting protein (AIP) gene. Endocrine Reviews 201334 239-277. (doi:10.1210/ er.2012-1013)

10 Madsen H, Borges MT, Kerr JM, Lillehei KO \& Kleinschmidt-Demasters BK. McCune-Albright syndrome: surgical and therapeutic challenges in GH-secreting pituitary adenomas. Journal of Neuro-Oncology 2011104 215-224. (doi:10.1007/s11060-010-0461-9)

11 Hansen MR \& Moffat JC. Osteosarcoma of the skull base after radiation therapy in a patient with McCune-Albright syndrome: case report. Skull Base 200313 79-83. (doi:10.1055/s-2003-40597)

12 Akintoye SO, Chebli C, Booher S, Feuillan P, Kushner H, Leroith D, Cherman N, Bianco P, Wientroub S, Robey PG et al. Characterization of gsp-mediated growth hormone excess in the context of McCuneAlbright syndrome. Journal of Clinical Endocrinology \& Metabolism 2002 87 5104-5112. (doi:10.1210/jc.2001-012022)

13 Li H, Ji C, Zong X \& Zhang Y. Height and weight standardized growth charts for Chinese children and adolescents aged 0 to 18 years. Chinese Journal of Pediatrics 200947 482-492. (doi:10.3760/cma.j.i ssn.0578-1310.2009.07.003)

14 Ji L, Lian L, Sun S \& Sun X. 19416 cases of serum alkaline phosphatase activity analysis of healthy adults. Chinese Journal of Laboratory Diagnosis 201115 683-684. (doi:10.3969/j.issn.10074287.2011.04.038)

$15 \mathrm{Lu} \mathrm{Q} \&$ Jia Z. Reference values of serum alkaline phosphatase for Chinese children and adolescents aged 0 to 18 years. Clinics in Laboratory Medicine 20096 1069-1070.

16 Weinstein LS, Shenker A, Gejman PV, Merino MJ, Friedman E \& Spiegel AM. Activating mutations of the stimulatory G protein in the McCune-Albright syndrome. New England Journal of Medicine 1991 325 1688-1695. (doi:10.1056/NEJM199112123252403)

17 Ozcan-Kara P, Mahmoudian B, Erbas B \& Erbas T. McCune-Albright syndrome associated with acromegaly and bipolar affective disorder. European Journal of Internal Medicine 200718 600-602. (doi:10.1016/j. ejim.2007.02.030)

18 Collins MT, Singer FR \& Eugster E. McCune-Albright syndrome and the extraskeletal manifestations of fibrous dysplasia. Orphanet Journal of Rare Diseases 20127 (Suppl 1) S4. (doi:10.1186/1750-1172-7-S1-S4)

19 Dal J, Feldt-Rasmussen U, Andersen M, Kristensen LO, Laurberg P, Pedersen L, Dekkers OM, Sorensen HT \& Jorgensen JO. Acromegaly incidence, prevalence, complications and long-term prognosis: a nationwide cohort study. European Journal of Endocrinology 2016175 181-190. (doi:10.1530/EJE-16-0117)

20 Salenave S, Boyce AM, Collins MT \& Chanson P. Acromegaly and McCune-Albright syndrome. Journal of Clinical Endocrinology \& Metabolism 201499 1955-1969. (doi:10.1210/jc.2013-3826)

21 Abs R, Beckers A, Van de Vyver FL, De Schepper A, Stevenaert A \& Hennen G. Acromegaly, multinodular goiter and silent polyostotic 
fibrous dysplasia. A variant of the McCune-Albright syndrome. Journal of Endocrinological Investigation 199013 671-675. (doi:10.1007/ BF03349592)

22 Scillitani A, Chiodini I, Carnevale V, Giannatempo GM, Frusciante V, Villella M, Pileri M, Guglielmi G, Di Giorgio A, Modoni S et al. Skeletal involvement in female acromegalic subjects: the effects of growth hormone excess in amenorrheal and menstruating patients. Journal of Bone and Mineral Research 199712 1729-1736. (doi:10.1359/ jbmr.1997.12.10.1729)

23 Collins MT, Kushner H, Reynolds JC, Chebli C, Kelly MH, Gupta A, Brillante B, Leet AI, Riminucci M, Robey PG et al. An instrument to measure skeletal burden and predict functional outcome in fibrous dysplasia of bone. Journal of Bone and Mineral Research 200520 219-226. (doi:10.1359/JBMR.041111)

24 Chanson P \& Salenave S. Acromegaly. Orphanet Journal of Rare Diseases 20083 17. (doi:10.1186/1750-1172-3-17)

25 Ringel MD, Schwindinger WF \& Levine MA. Clinical implications of genetic defects in G proteins. The molecular basis of McCune-Albright syndrome and Albright hereditary osteodystrophy. Medicine $1996 \mathbf{7 5}$ 171-184. (doi:10.1097/00005792-199607000-00001)

26 Vortmeyer AO, Glasker S, Mehta GU, Abu-Asab MS, Smith JH, Zhuang Z, Collins MT, Oldfield EH. Somatic GNAS mutation causes widespread and diffuse pituitary disease in acromegalic patients with McCune-Albright syndrome. Journal of Clinical Endocrinology \& Metabolism 201297 2404-2413. (doi:10.1210/jc.2012-1274)

27 Ludecke DK \& Abe T. Transsphenoidal microsurgery for newly diagnosed acromegaly: a personal view after more than 1,000 operations. Neuroendocrinology 200683 230-239. (doi:10.1159/000095533)

28 Akintoye SO, Kelly MH, Brillante B, Cherman N, Turner S, Butman JA, Robey PG \& Collins MT. Pegvisomant for the treatment of gspmediated growth hormone excess in patients with McCune-Albright syndrome. Journal of Clinical Endocrinology \& Metabolism 200691 2960-2966. (doi:10.1210/jc.2005-2661)

29 Shen M, Shou X, Wang Y, Zhang Z, Wu J, Mao Y, Li S \& Zhao Y. Effect of presurgical long-acting octreotide treatment in acromegaly patients with invasive pituitary macroadenomas: a prospective randomized study. Endocrine Journal 201057 1035-1044. (doi:10.1507/endocri.K10E-203)

30 Collins MT, Singer FR \& Eugster E. McCune-Albright syndrome and the extraskeletal manifestations of fibrous dysplasia. Orphanet Journal of Rare Diseases 20127 (Suppl 1) S4. (doi:10.1186/1750-1172-7-S1-S4)

31 Liu F, Li W, Yao Y, Li G, Yang Y, Dou W, Zhong D, Wang L, Zhu X, $\mathrm{Hu} \mathrm{H}$ et al. A case of McCune-Albright syndrome associated with pituitary GH adenoma: therapeutic process and autopsy. Journal of Pediatric Endocrinology and Metabolism 201124 283-287. (doi:10.1515/ jpem.2011.178)

32 Zumkeller W, Jassoy A, Lebek S \& Nagel M. Clinical, endocrinological and radiography features in a child with McCune-Albright syndrome and pituitary adenoma. Journal of Pediatric Endocrinology and Metabolism 200114 553-559. (doi:10.1515/jpem.2001.14.5.553)

33 Bhansali A, Sharma BS, Sreenivasulu P, Singh P, Vashisth RK \& Dash RJ. Acromegaly with fibrous dysplasia: McCune-Albright syndrome - clinical studies in 3 cases and brief review of literature. Endocrine Journal 200350 793-799. (doi:10.1507/endocrj.50.793)

34 Zacharin M. Paediatric management of endocrine complications in McCune-Albright syndrome. Journal of Pediatric Endocrinology and Metabolism 200518 33-41. (doi:10.1515/JPEM.2005.18.1.33)

35 Sargin H, Gozu H, Bircan R, Sargin M, Avsar M, Ekinci G, Yayla A, Gulec I, Bozbuga M, Cirakoglu B et al. A case of McCune-Albright syndrome associated with Gs alpha mutation in the bone tissue. Endocrine Journal 200653 35-44. (doi:10.1507/endocrj.53.35)

36 Papadopoulou M, Doula S, Kitsios K, Kaltsas T \& Kosta K. A boy with McCune-Albright syndrome associated with GH secreting pituitary microadenoma. Clinical findings and response to treatment. Hormones 20065 205-209. (doi:10.14310/ horm.2002.11186)

37 Sang Hun Sung HDY, Ho Sang Shon, Hong Tae Kim, Woo Young Choi, Chang Jin Seo \& Joo Hyoung Lee. A Case of McCune-Albright syndrome with associated multiple endocrinopathies FAU - Sung, Sang Hun FAU - Yoon, Hyun Dae FAU - Shon, Ho Sang FAU - Kim, Hong Tae FAU - Choi, Woo Young FAU - Seo, Chang Jin FAU - Lee, Joo Hyoung. Korean Journal of Internal Medicine 200722 45-50. (doi:10.3904/kjim.2007.22.1.45)

38 Tajima T, Tsubaki J, Ishizu K, Jo W, Ishi N \& Fujieda K. Case study of a 15-year-old boy with McCune-Albright syndrome combined with pituitary gigantism: effect of octreotide-long acting release (LAR) and cabergoline therapy. Endocrine Journal 200855 595-599. (doi:10.1507/ endocri.K07E-042)

39 Almeida JP, Albuquerque LA, Ferraz CL, Mota I, Gondim J \& Ferraz TM. McCune-Albright syndrome and acromegaly: hormonal control with use of cabergoline and long-acting somatostatin-case report. Arquivos Brasileiros de Endocrinologia \& Metabologia 200953 102-106. (doi:10.1590/s0004-27302009000100015)

40 Baszko-Blaszyk D, Slynko J, Liebert W, Sosnowski P, Sowinski J \& Wasko R. Difficulties in diagnosis and treatment of acromegaly in a patient with a McCune-Albright syndrome. A case report and a review of literature. Neuroendocrinology Letters 201031 594-596.

41 Sakayama K, Sugawara Y, Kidani T, Fujibuchi T, Kito K, Tanji N \& Nakamura A. Polyostotic fibrous dysplasia with gigantism and huge pelvic tumor: a rare case of McCune-Albright syndrome. International Journal of Clinical Oncology 201116 270-274. (doi:10.1007/s10147010-0127-9)

42 Natarajan MS, Prabhu K, Chacko G, Rajaratnam S \& Chacko AG. Endoscopic transsphenoidal excision of a GH-PRL-secreting pituitary macroadenoma in a patient with McCune-Albright syndrome. British Journal of Neurosurgery 201226 104-106. (doi:10.3109/02688697.2011. 591852)

43 Boyce AM, Glover M, Kelly MH, Brillante BA, Butman JA, Fitzgibbon EJ, Brewer CC, Zalewski CK, Cutler Peck CM, Kim HJ et al. Optic neuropathy in McCune-Albright syndrome: effects of early diagnosis and treatment of growth hormone excess. Journal of Clinical Endocrinology \& Metabolism 201398 E126-E134. (doi:10.1210/ jc.2012-2111)

Received 21 August 2016

Revised version received 9 December 2016

Accepted 22 December 2016 